FULL TEXT ARTICLE

\title{
Cachexia \& debility diagnoses in hospitalized children and adolescents with complex chronic conditions: evidence from the Kids' Inpatient Database
}

Bryce A Van Doren, Debosree Roy, Joshua M Noone, Christopher M Blanchette, Susan T Arthur

University of North Carolina at Charlotte, NC, USA

\section{Citation}

Van Doren BA, Roy D, Noone JM, Blanchette CM, Arthur ST. Cachexia \& debility diagnoses in hospitalized children and adolescents with complex chronic conditions: evidence from the Kids' Inpatient Database. Drugs in Context 2015; 4: 212277 . doi: $10.7573 /$ dic. 212277

\section{Copyright}

Copyright @ 2015 Van Doren BA, Roy D, Noone JM, Blanchette CM, Arthur ST. Distributed under the terms of the Creative Commons License Deed CC BY NC ND 3.0 which allows anyone to copy, distribute, and transmit the articles provided it is properly attributed in the manner specified below. No commercial use without permission.

\section{Correct attribution}

Copyright @ 2015 Van Doren BA, Roy D, Noone JM, Blanchette CM, Arthur ST. http://dx.doi.org/10.7573/dic.212277. Published by Drugs in Context under Creative Commons Attributions License Deed CC BY NC ND 3.0.

\section{Article URL}

http://www.drugsincontext.com/cachexia-debilitydiagnoses-hospitalized-children-adolescents-complexchronic-conditions-evidence-kids-inpatient-database

\section{Correspondence}

Bryce A Van Doren, University of North Carolina at Charlotte, College of Health and Human Services, 9201 University City Blvd, Charlotte, NC 28223, USA. bvandore@uncc.edu

\section{Provenance}

Submitted, externally peer reviewed

\section{Dates}

Submitted: 27 January 2015

Revised manuscript submitted: 17 February 2015

Publication date: 27 February 2015

\section{Publisher and contact information}

Drugs in Context is published by Just Medical Media Ltd Undermount, Rydal, Ambleside, Cumbria, LA22 9LT, UK ISSN 1740-4398

Just Medical Media Limited is registered in England Number 6891187

VAT GB 945171322

\section{Julia Savory}

Head of Digital Publishing and Submissions Management julia@justmedicalmedia.com

Tel: +44(0)1242910999

\section{Abbreviations}

CCCs, complex chronic conditions; HIV, human immunodeficiency virus; KID, Kids' Inpatient Database; PDD, primary discharge diagnosis; TNF-a, tumor necrosis factor-alpha 


\section{Specialist Editor-in-Chief}

\section{Deborah P Lubeck, PhD}

Vice President, Outcomes Insights Inc, CA, USA

\section{Specialist editorial board members}

\section{Charles Bennett, MD, PhD}

Endowed Chair, Center for Medication Safety and Efficacy, South Carolina College of Pharmacy Health Services, Columbia, SC, USA

\section{Susan H Boklage, MS MPH}

Associate Director, Health Economics and Outcomes Research, Otsuka America Pharmaceutical, Inc, Princeton, NJ, USA

\section{Pamela Daniels, MBA, MPH, PhD}

Epidemiologist, Morehouse School of Medicine, 720 Westview Drive, SW, MRC Annex S-10, Atlanta, GA, USA

\section{David M Latini, PhD}

Assistant Adjunct Professor, Scott Department of Urology, Baylor College of Medicine, Houston, Texas, USA

\section{Vinit Nair, BPharm, MS, RPh}

Director and Practice Lead - Government and Academic Research, Comprehensive Health Insights, Humana Inc, Miramar, FL, USA

\section{Dr John H Walker, OCT, MBA, PhD}

Professor, Goodman School of Business, Brock University, St Catharines, Ontario, Canada

\section{Junhua Yu}

Assistant Professor, Social, Behavioral and Administrative Sciences, Touro University College of Pharmacy, Vallejo, CA, USA

\section{Group Editor-in-Chief}

\section{Christopher Blanchette, PhD, MBA}

Associate Dean for Research and Research Associate Professor in the Department of Public Health Sciences at the University of North Carolina and Director of Health Economics \& Outcomes Research at Otsuka America Pharmaceutical Inc, USA

\section{Expert Advisers - Epidemiology and biostatistics}

\section{Alex K Exuzides, PhD}

Director, ICON Clinical Research Inc, California, USA

\section{Professor Scott L Friedman, MD}

Fishberg Professor of Medicine, Dean for Therapeutic Discovery Chief, Division of Liver Diseases, Mount Sinai School of Medicine, New York, USA

\section{Carl De Moor, PhD}

Senior Principal, Epidemiology and Leader Epidemiology, Safety and Risk Management Center of Excellence Americas, IMS Health Inc, USA

\section{Dr John H Walker, OCT, MBA, PhD}

Professor, Goodman School of Business, Brock University, St Catharines, Ontario, Canada

\section{Expert Adviser - Publication Ethics}

\section{Dr Elizabeth (Liz) Wager}

Publications Consultant, Princes Risborough, UK; Visiting Professor, University of Split School of Medicine, Croatia; Former Chair (2009-2012), Committee on Publication Ethics (COPE)

\section{Editor-in-Chief Emeritus}

Dr George Kassianos, FRCGP, FESC, FBGTHA, FAcadMEd, FFTM RCPSGlasg

General Practitioner, Bracknell, Berkshire, UK; President British Global \& Travel Health Association Fellow of the European Society of Cardiology

\section{Specialist Advisor - Clinical Pharmacology}

Dr Richard White, MA, PhD

Consulting Partner and Director, Oxford PharmaGenesis Ltd, UK

To see the full Drugs in Context Editorial Board, please visit www.drugsincontext.com/editorial-board 


\title{
Cachexia \& debility diagnoses in hospitalized children and adolescents with complex chronic conditions: evidence from the Kids' Inpatient Database
}

\author{
Bryce A Van Doren, Debosree Roy, Joshua M Noone, \\ Christopher M Blanchette, and Susan T Arthur
}

University of North Carolina at Charlotte, NC, USA

\section{Citation}

Van Doren BA, Roy D, Noone JM, Blanchette CM, Arthur ST. Cachexia \& debility diagnoses in hospitalized children and adolescents with complex chronic conditions: evidence from the Kids' Inpatient Database. Drugs in Context 2015; 4: 212277. doi: $10.7573 /$ dic. 212277

\section{Abstract}

Objective: To characterize the frequency, cost, and hospitalreported outcomes of cachexia and debility in children and adolescents with complex chronic conditions (CCCs).

Methods: We identified children and adolescents (aged $\leq 20$ years) with CCCs, cachexia, and debility in the Kids' Inpatient Database [Healthcare Cost and Utilization Project, Agency for Healthcare Research \& Quality]. We then compared the characteristics of patients and hospitalizations, including cost and duration of stay, for CCCs with and without cachexia and/ or debility. We examined factors that predict risk of inpatient mortality in children and adolescents with CCCs using a logistic regression model. We examined factors that impact duration of stay and cost in children and adolescents with CCCs using negative binomial regression models. All costs are reported in US dollars in 2014 using Consumer Price Index inflation adjustment.
Results: We estimated the incidence of hospitalization of cachexia in children and adolescents with CCCs at 1,395 discharges during the sample period, which ranged from 277 discharges in 2003 to 473 discharges in 2012. We estimated the incidence of hospitalization due to debility in children and adolescents with CCCs at 421 discharges during the sample period, which ranged from 39 discharges in 2003 to 217 discharges in 2012. Cachexia was associated with a $60 \%$ increase in the risk of inpatient mortality, whereas debility was associated with a $40 \%$ decrease in the risk of mortality. Cachexia and debility increased duration of stay in hospital (17\% and $39 \%$ longer stays, respectively). Median cost of hospitalization was $\$ 15,441.59$ and $\$ 23,796.16$ for children and adolescents with cachexia and debility, respectively.

Conclusions: Incidence of hospitalization for cachexia in children and adolescents with CCCs is less than that for adults but the frequency of cachexia diagnoses increased over time. Estimates of the incidence of hospitalization with debility in children and adolescents with CCCs have not been reported, but our study demonstrates that the frequency of these discharges is also increasing.

Keywords: adolescent, cachexia, child, complex chronic conditions, cost analysis, debility, HIV, pediatrics.

\section{Introduction}

Consensus definitions of cachexia (International Classification of Disease, 9th revision, Clinical Modification (ICD-9-CM) code 799.4) and debility (ICD-9-CM code 799.3) have been slow to emerge. In fact, these conditions are classified in the ICD-9CM as "ill-defined conditions" [1]. Cachexia is associated with progressive wasting of adipose tissue and skeletal muscle. It is commonly a sequela from complex chronic conditions (CCCs) such as cancer and infection by the human immunodeficiency virus (HIV) in adults [2,3]. Debility refers to weakness, fatigue,

and loss of strength. Debility has been demonstrated to be a marker for adult mortality [4]. Cachexia has been described in children and adolescents with CCCs, including (but not limited to) those with chronic kidney disease, cancer, liver disease, and Crohn's disease [5-10]. Studies on inpatient mortality in children have attributed $\leq 24 \%$ of deaths to CCCs as an underlying cause $[11,12]$. Cachexia increases morbidity and mortality in patients if present as a sequela with any chronic condition [13]. However, its ramifications on healthcare utilization and patient outcomes (especially in children) are important topics of study. Little is known, however, about the characteristics of patients and 
hospitalizations, including inpatient mortality risk, duration of stay, and cost associated with cachexia and debility in children and adolescents with CCCs.

Several definitions for cachexia have emerged within the past decade. The 2008 Cachexia Consensus Conference formulated the definition of the syndrome as "... a complex metabolic syndrome associated with underlying illness and characterized by loss of muscle with or without loss of fat mass. The prominent clinical feature of cachexia is weight loss in adults ... or growth failure in children (excluding endocrine disorders)" [14].

The definition from the 2008 Cachexia Consensus Conference has been updated. However, it remains important because of its inclusion of children, which more recent definitions appear to omit, such as those from Muscaritoli et al [2]. Building upon the definition from the 2008 Cachexia Consensus Conference, Feron et al established a diagnostic criterion for cachexia: unintentional weight loss $>5 \%$, particularly in cancer patients [15]. This diagnostic criterion was validated recently in an international sample of $\approx 1,100$ patients with advanced cancer [16]. Simple supplemental nutrition to arrest stunting, wasting, and other manifestations of cachexia in children has not been fruitful $[17,18]$. Therefore, more work is needed to fully characterize the medical burden of cachexia and debility in children to support development of successful treatment plans.

A consensus definition or diagnostic criterion for debility is lacking. Despite this lack of consensus definition, debility is consistently one of the top non-cancer diagnoses for admission to hospices $[15,19]$. Given their proximity in the ICD-9-CM and their mutual association with chronic and terminal conditions, one could infer that cachexia and debility are closely related. Indeed, this connection has been postulated in cancer patients [20-22].

Prevalence of CCCs in children has been increasing during the past decade because advanced medical technologies are increasing life-expectancy in children with these conditions [23]. Given the increased prevalence of CCCs, we hypothesized that the incidence of cachexia- and debility-related hospitalizations will have increased over the past decade. By characterizing cachexia- and debility-related hospitalizations, we also sought to test if the two conditions occur together. In adults, cachexia and debility are associated with increased mortality; we sought to ascertain if this is also true for children. Finally, we examined the predictors of inpatient mortality, duration of stay in hospital, and cost of care. By identification of the medical burden of cachexia and debility, we will be able to support the design of appropriate treatment plans for children and adolescents with CCCs.

\section{Methods}

Results from the 2003-2012 release of the Kids' Inpatient Database (KID) were acquired from the Healthcare Cost and Utilization Project (Agency for Healthcare Research and Quality) and analyzed. A new version of the KID is released every third year, so the data utilized in the present study include four data releases of the KID. Each release of data includes an $80 \%$ sample of discharge summaries of non-birth, hospitalizations in children and adolescents (age $\leq 20$ years) across the USA, representing over 3 million inpatient hospitalizations. The four data releases comprise $12,722,560$ unique discharge summaries.

Each discharge summary was searched for diagnoses of cachexia, debility, and CCCs. Each record in the KID includes $\leq 25$ discharge diagnoses as specified by ICD-9-CM diagnosis codes. The dataset was restricted to children and adolescents with CCCs (Appendix 1). CCCs were classified by the body system affected (i.e., neuromuscular, cardiovascular, respiratory, renal, gastrointestinal, hematologic, metabolic, malignancy, other). Multiple systems may be affected in some children. Thus, when reporting these results, frequencies did not add up to $100 \%$. Records were also flagged if they contained cachexia (ICD-9-CM 799.4) or debility (ICD-9-CM 799.3). We defined cachexia- and debility-related hospitalizations as a discharge in which either condition (or both) appeared as one of the 25 discharge diagnoses. Cost of care was calculated for each discharge using the cost-to-charge ratio from the KID. All costs are reported in US \$ using the Consumer Price Index conversion factor for each year.

Descriptive statistics (i.e., counts, frequencies, averages) were calculated for diagnoses and for characteristics of patients and hospitalizations, which included demographics, duration of stay, and cost. We grouped hospital discharges using the following age categories (in years): $\leq 4,5-8,9-12$, 13-16, and 17-20. The agreement for use of data from the KID stipulates that cell sizes $<10$ may not be reported. Thus, a small number of values in descriptive statistics had to be suppressed. The sample weight assigned to each discharge summary was used to calculate an estimate of the incidence of hospitalization for each condition. Characteristics of demographics and hospitalizations were compared for cachexia, debility, and CCCs (without either condition) using univariate and bivariate statistical tools, including frequencies and chi-square tests. Comparison of duration of stay and cost between conditions was made using the Wilcoxon-Mann-Whitney test, a non-parametric equivalent to the Student's t-test.

We also examined factors that affected the risk of inpatient death, hospitalization stay, and cost of care. Risk of patient death was calculated using logistic regression. In the logistic model, inpatient death was treated as the dependent variable, and cachexia and debility as primary independent variables, with control of demographic characteristics, hospitalization characteristics, and the body system affected. Duration of stay and cost of care were examined using negative binomial models. In these models, duration of stay and cost of care were dependent variables and, like the logistic regression model, 
cachexia and debility were primary independent variables, with control of demographic characteristics, hospitalization characteristics, and the body system affected.

\section{Results}

We identified 558,215 hospitalizations (4.39\% of the overall KID sample) that were related to CCCs. Of these hospitalizations, $908(0.16 \%)$ and $287(0.05 \%)$ included diagnoses of cachexia and debility, respectively (Table 1). Fewer than 10 hospitalizations during the sample period included a diagnosis of cachexia and debility. Across the four sample years, we estimated the incidence of cachexia- and debility-related hospitalizations to be 1,395 and 421, respectively. Cachexia and debility were coded as secondary diagnoses in all but two discharges (in which conditions were coded as the primary discharge diagnosis (PDD)). The frequency of cachexia-related hospitalizations increased across the sample period from 160 hospitalizations in 2003 to 332 hospitalizations in 2012 (weighted estimate: 277 cases in 2003 to 473 cases in 2012). The frequency of debility-related hospitalizations also increased across the sample period from 24 hospitalizations in 2003 to 153 hospitalizations in 2012 (weighted estimate: 39 cases in 2003 to 217 cases in 2012).

Characteristics of demographics and hospitalizations are shown in Table 1. Proportion of hospitalizations resulting in inpatient death varied between conditions; $5.73 \%$ of cachexia hospitalizations, $2.44 \%$ of debility hospitalizations, and $2.76 \%$ of hospitalizations unrelated to cachexia and debility resulted in inpatient death. Cachexia was most common in AfricanAmericans (31.50\% of cachexia hospitalizations), followed closely by Caucasians (29.96\%). Debility was more common in Caucasians than in African-Americans (43.21\% and 19.16\% of debility hospitalizations, respectively). This trend followed a similar pattern in CCCs without cachexia or debility: $39.03 \%$ of these hospitalizations were in Caucasians and $15.53 \%$ in African-Americans. For all conditions, more hospitalizations occurred in males than in females. Median age of cachexia patients was 16 (interquartile range (IQR), 10-19) years. Median age of debility patients was 18 (IQR, 12-19) years. Median age for both conditions was significantly older than for the average CCC patient without cachexia $(p<0.0001)$ or debility $(p<0.0001$; 12 (IQR: 3-17) years).

Fewer than 10 hospitalizations for either condition included a minor loss of function. Major and extreme losses of function were common in hospitalizations related to cachexia and debility. For cachexia, $45.59 \%$ and $36.01 \%$ of hospitalizations had major or extreme losses of function, respectively. For debility, $42.51 \%$ and $41.81 \%$ of hospitalizations had major or extreme losses of function, respectively. In contrast, just $31.25 \%$ and $20.57 \%$ of hospitalizations unrelated to cachexia or debility had major or extreme loss of function, respectively.
Cachexia was most commonly associated with metabolic (28.30\% of cachexia hospitalizations), hematologic (27.09\%) and neuromuscular (21.70\%) CCCs. With regard to debility, $<10$ hospitalizations were related to hematologic CCCs. Debility was most commonly associated with metabolic (48.43\%), cardiovascular (18.12\%) and neuromuscular (17.77\%) CCCs. The most common sites of CCCs without cachexia or debility were cardiovascular (42.02\% of hospitalizations), followed by metabolic (13.38\%) and other congenital or genetic disorders (12.96\%).

The most common PDD varied between conditions. The most common PDD in cachexia-related hospitalizations were HIV (ICD-9-CM 042; n=172; 18.94\%), pneumonia (ICD-9-CM $486 ; n=34 ; 3.74 \%$ ), and failure to thrive (ICD-9-CM 783.41; $\mathrm{n}=28 ; 3.08 \%)$. The most common PDD in debility-related hospitalizations were admissions for rehabilitation (ICD-9-CM V57.89; $n=51 ; 17.77 \%$ ), septicemia (ICD-9-CM 03.89; $n=13 ; 4.53 \%$ ), and anti-neoplastic chemotherapy (ICD-9-CM V58.11; $\mathrm{n}=10$; $3.48 \%$ ). If neither cachexia nor debility were included on the discharge summary, the most common PDD were acute febrile mucocutaneous lymph node syndrome (MCLS) (ICD-9-CM 446.1; $n=12,190 ; 2.19 \%$ ), pneumonia (ICD-9-CM 486; $n=11,189$; $2.01 \%)$, and congenital anomalies of the skull and face bones (ICD-9-CM 756.0; $\mathrm{n}=10,178 ; 1.83 \%)$.

A total of $31.89 \%$ of CCC hospitalizations without cachexia or debility had a major procedure in the operating room, but far fewer patients with cachexia (17.65\%) and debility (16.96\%) had a major procedure in the operating room (Table 2). Heart transplantation was the most common major procedure in the operating room for cachexia patients $(n<10 ;<1.01 \%)$. When examined more broadly, the most common medical procedures undertaken during hospitalizations for cachexia were parenteral infusion of concentrated nutritional substances $(n=39 ; 5.93 \%)$, continuous invasive mechanical ventilation for $96 \mathrm{~h}$ consecutively $(\mathrm{n}=35 ; 5.32 \%)$, and transfusion of packed cells $(n=34 ; 5.17 \%)$. Implantation of a cardioverter/defibrillator was the most common major procedure in the operating room for debility $(\mathrm{n}<10 ;<3.48 \%)$. When examined more broadly, the most common medical procedures carried out during hospitalizations related to debility were continuous invasive mechanical ventilation for $96 \mathrm{~h}$ consecutively ( $n=26 ; 11.35 \%$ ), continuous invasive mechanical ventilation for $<96 \mathrm{~h}$ consecutively $(n=17 ; 7.42 \%)$, and venous catheterization $(n=16 ; 6.99 \%)$.

Medicaid was the most common primary expected payer for CCC-related hospitalizations, including $59.91 \%$ of cachexiarelated hospitalizations and $46.34 \%$ of debility-related hospitalizations. (Medicaid was also the most common primary payer for discharges without cachexia and debility [49.49\%].) The overall median cost of hospitalization was higher for patients with debility $(\$ 23,796.16$ [IQR: $\$ 7,803.91-55,889.35])$ than patients with cachexia $(\$ 15,441.59$ [IQR: $\$ 6,572.28-$ 35,619.59]; $\mathrm{p}<0.01$ ) (Table 2). However, there was no significant difference in median cost per hospitalization day between debility $(\$ 1,694.68$ [IQR: $\$ 1,056.45-2,927.34])$ and cachexia 
Table 1. Characteristics of demographics and hospitalizations for children and adolescents with complex chronic disease with cachexia and debility, including estimates of the incidence of hospitalization.

\begin{tabular}{|c|c|c|c|c|}
\hline & Cachexia & Debility & $\begin{array}{l}\text { Cachexia or } \\
\text { debility }\end{array}$ & $\begin{array}{l}\text { Complex chronic condition } \\
\text { without cachexia or debility }\end{array}$ \\
\hline Incidence estimate & 1,395 & 421 & 1,808 & 839,288 \\
\hline Population (n) & 908 & 287 & 1,189 & 557,026 \\
\hline Inpatient death (\%) & 5.73 & 2.44 & 4.79 & 2.76 \\
\hline Age (median) & 16 & 18 & 17 & 12 \\
\hline Interquartile range & $10-19$ & $12-19$ & $12-19$ & $3-17$ \\
\hline \multicolumn{5}{|l|}{ Age category (\%) } \\
\hline$\leq 4$ years & 17.84 & 15.33 & 17.24 & 70.25 \\
\hline $5-8$ years & 5.51 & 5.57 & 5.55 & 5.25 \\
\hline $9-12$ years & 12.22 & 8.71 & 11.35 & 5.08 \\
\hline 13-16 years & 22.14 & 11.15 & 19.51 & 6.89 \\
\hline $17-20$ years & 42.29 & 59.23 & 46.34 & 12.53 \\
\hline \multicolumn{5}{|l|}{ Ethnicity } \\
\hline Caucasian & 29.96 & 43.21 & 32.97 & 39.03 \\
\hline African-American & 31.50 & 19.16 & 28.60 & 15.53 \\
\hline Hispanic & 17.40 & 14.98 & 16.90 & 19.19 \\
\hline Other & 21.15 & 22.65 & 21.53 & 26.25 \\
\hline \multicolumn{5}{|l|}{ Sex (\%) } \\
\hline Male & 58.37 & 59.58 & 58.87 & 53.26 \\
\hline Female & 41.63 & 40.42 & 41.13 & 46.45 \\
\hline Not specified & 0.00 & 0.00 & 0.00 & 0.29 \\
\hline \multicolumn{5}{|l|}{ Region (\%) } \\
\hline North East & 22.47 & 4.88 & 18.33 & 16.15 \\
\hline Midwest & 17.07 & 28.57 & 19.85 & 22.27 \\
\hline South & 42.18 & 52.96 & 44.58 & 36.82 \\
\hline West & 18.28 & 13.59 & 17.24 & 24.76 \\
\hline \multicolumn{5}{|l|}{ Hospital location (\%) } \\
\hline Rural & 2.64 & $<3.48$ & 2.52 & 3.18 \\
\hline Urban (non-teaching) & 11.01 & 20.91 & 13.20 & 21.47 \\
\hline Urban (teaching) & 82.93 & 74.91 & 81.16 & 71.41 \\
\hline Not specified & 3.42 & $<3.48$ & 3.12 & 3.94 \\
\hline \multicolumn{5}{|l|}{ Expected primary payer } \\
\hline Medicare & 2.97 & 3.14 & 3.03 & 0.75 \\
\hline Medicaid & 59.91 & 46.34 & 56.60 & 49.49 \\
\hline Private & 26.65 & 42.86 & 30.61 & 41.93 \\
\hline Self-payer & 4.41 & 3.83 & 4.29 & 2.94 \\
\hline Other & 6.06 & 3.83 & 5.47 & 4.89 \\
\hline \multicolumn{5}{|l|}{ Loss of function (\%) } \\
\hline Minor & $<1.01$ & $<3.48$ & 1.01 & 18.11 \\
\hline Moderate & 17.51 & 13.94 & 16.74 & 29.76 \\
\hline Major & 45.59 & 42.51 & 44.83 & 31.25 \\
\hline Extreme & 36.01 & 41.81 & 37.34 & 20.57 \\
\hline Not specified & $<1.01$ & 0.00 & $<0.84$ & 0.31 \\
\hline
\end{tabular}


Table 1. Characteristics of demographics and hospitalizations for children and adolescents with complex chronic disease with cachexia and debility, including estimates of the incidence of hospitalization (continued).

\begin{tabular}{|c|c|c|c|c|}
\hline & Cachexia & Debility & $\begin{array}{l}\text { Cachexia or } \\
\text { debility }\end{array}$ & $\begin{array}{l}\text { Complex chronic condition } \\
\text { without cachexia or debility }\end{array}$ \\
\hline \multicolumn{5}{|l|}{ Body system affected (\%) } \\
\hline Neuromuscular & 21.70 & 17.77 & 20.86 & 10.59 \\
\hline Cardiovascular & 16.74 & 18.12 & 17.16 & 42.02 \\
\hline Respiratory & 2.53 & 5.57 & 3.28 & 12.41 \\
\hline Renal & $<1.01$ & 0.00 & $<0.84$ & 0.60 \\
\hline Gastrointestinal & 8.48 & 7.32 & 8.24 & 9.77 \\
\hline Hematologic/immunodeficiency & 27.09 & $<3.48$ & 21.11 & 3.63 \\
\hline Metabolic & 28.30 & 48.43 & 32.80 & 13.38 \\
\hline Malignancy & $<1.01$ & $<3.48$ & $<0.84$ & 2.10 \\
\hline $\begin{array}{l}\text { Other congenital or genetic } \\
\text { disorder }\end{array}$ & 4.74 & 6.62 & 5.21 & 12.96 \\
\hline
\end{tabular}

Table 2. Duration of stay, hospitalization cost, and number of diagnoses.

\begin{tabular}{|c|c|c|c|c|}
\hline & Cachexia & Debility & $\begin{array}{l}\text { Cachexia or } \\
\text { debility }\end{array}$ & $\begin{array}{l}\text { Complex chronic } \\
\text { condition without } \\
\text { cachexia or debility }\end{array}$ \\
\hline \multicolumn{5}{|l|}{ Duration of stay (days) } \\
\hline Median number of days & 8 & 12 & 9 & 5 \\
\hline IQR & 4 to 17 & 7 to 24 & 5 to 19 & 2 to 16 \\
\hline Sum total hospital days & 14,656 & 5,353 & 19,337 & $9,473,378$ \\
\hline \multicolumn{5}{|l|}{ Comorbidities (diagnoses) } \\
\hline Median number of comorbidities & 12 & 15 & 13 & 7 \\
\hline IQR & 9 to 16 & 10 to 20 & 9 to 17 & 4 to 11 \\
\hline \multicolumn{5}{|l|}{ Procedures } \\
\hline Median number of procedures & 2 & 3 & 2 & 2 \\
\hline IQR & 0 to 4 & 1 to 6 & 0 to 4 & 0 to 5 \\
\hline $\begin{array}{l}\text { Percentage of patients with a major } \\
\text { procedure in the operating room }\end{array}$ & $17.65 \%$ & $16.96 \%$ & $17.58 \%$ & $31.89 \%$ \\
\hline \multicolumn{5}{|l|}{ Hospitalization cost (\$) } \\
\hline Median cost & $15,441.59$ & $23,796.16$ & $16,125.23$ & $9,726.76$ \\
\hline IQR cost & $6,572.28$ to $35,619.59$ & $7,830.91$ to $55,889.35$ & $6,619,81$ to $38,581.15$ & $3,505.87$ to $33,190.15$ \\
\hline Median cost/hospitalization day & $1,787.69$ & $1,694.68$ & $1,785.60$ & $1,723.28$ \\
\hline IQR cost/hospitalization day & $1,182.02$ to 2707.81 & $1,056.45$ to $2,927.34$ & $1,149.15$ to $2,717.58$ & $1,057.34$ to $2,877.14$ \\
\hline Sum total cost & $16,757,716$ & $5,419,216$ & $22,115,696$ & $12,363,214,271$ \\
\hline
\end{tabular}

(\$1,787.69 [IQR: \$1,182.02-2,707.81]; $\mathrm{p}=0.49)$. Median duration of stay for a patient with debility (12 [IQR: 7-24] days) was significantly longer than in patients with cachexia (8 [IQR: 4-17] days; $p<0.01)$. The sum total cost of care for patients with cachexia and debility in KID was $\$ 22,115,696$ during sample periods $(\approx \$ 16.77$ million for cachexia and $\approx \$ 5.42$ million for debility). Using the sampling weights included in the KID, we estimated the national annual cost of hospitalization care for 
Table 3. Predictors of inpatient mortality in children and adolescents with complex chronic conditions (logistic regression model).

\begin{tabular}{|c|c|c|c|}
\hline & OR & LCI & UCI \\
\hline \multicolumn{4}{|l|}{ Cachexia } \\
\hline Not diagnosed & \multicolumn{3}{|c|}{ Reference } \\
\hline Diagnosed & 1.60 & 1.17 & 2.18 \\
\hline \multicolumn{4}{|l|}{ Debility } \\
\hline Not diagnosed & \multicolumn{3}{|c|}{ Reference } \\
\hline Diagnosed & 0.60 & 0.28 & 1.29 \\
\hline \multicolumn{4}{|l|}{ Age (years) } \\
\hline$\leq 4$ & 1.10 & 1.02 & 1.18 \\
\hline $5-8$ & 0.55 & 0.48 & 0.64 \\
\hline $9-12$ & 0.78 & 0.69 & 0.89 \\
\hline $13-16$ & 0.92 & 0.82 & 1.03 \\
\hline $17-20$ & \multicolumn{3}{|c|}{ Reference } \\
\hline \multicolumn{4}{|l|}{ Ethnicity } \\
\hline Caucasian & \multicolumn{3}{|c|}{ Reference } \\
\hline African-American & 1.23 & 1.17 & 1.30 \\
\hline Hispanic & 1.02 & 0.97 & 1.08 \\
\hline Other & 1.16 & 1.11 & 1.21 \\
\hline \multicolumn{4}{|l|}{ Sex } \\
\hline Female & \multicolumn{3}{|c|}{ Reference } \\
\hline Male & 1.01 & 0.97 & 1.04 \\
\hline \multicolumn{4}{|l|}{ Region } \\
\hline North East & \multicolumn{3}{|c|}{ Reference } \\
\hline Midwest & 0.96 & 0.90 & 1.02 \\
\hline South & 1.04 & 0.99 & 1.10 \\
\hline West & 1.02 & 0.96 & 1.08 \\
\hline \multicolumn{4}{|l|}{ Hospital location } \\
\hline Rural & \multicolumn{3}{|c|}{ Reference } \\
\hline Urban (non-teaching) & 1.00 & 0.85 & 1.18 \\
\hline Urban (teaching) & 1.36 & 1.16 & 1.59 \\
\hline
\end{tabular}

\begin{tabular}{|c|c|c|c|}
\hline \multicolumn{4}{|l|}{ Expected primary payer } \\
\hline Private & \multicolumn{3}{|c|}{ Reference } \\
\hline Medicare & 0.67 & 0.51 & 0.88 \\
\hline Medicaid & 1.03 & 0.99 & 1.08 \\
\hline Self-payer & 2.20 & 2.00 & 2.42 \\
\hline \multicolumn{4}{|l|}{ Loss of function (\%) } \\
\hline Minor & \multicolumn{3}{|c|}{ Reference } \\
\hline Moderate & 0.99 & 0.86 & 1.16 \\
\hline Major & 6.13 & 5.42 & 6.94 \\
\hline Extreme & 43.96 & 39.98 & 49.58 \\
\hline \multicolumn{4}{|l|}{ Median household income } \\
\hline First quartile (lowest) & 1.21 & 1.15 & 1.28 \\
\hline Second quartile & 1.16 & 1.10 & 1.22 \\
\hline Third quartile & 1.04 & 0.98 & 1.10 \\
\hline Fourth quartile (highest) & \multicolumn{3}{|c|}{ Reference } \\
\hline \multicolumn{4}{|c|}{ Body system affected (reference is not affected) } \\
\hline Neuromuscular & 0.75 & 0.68 & 0.83 \\
\hline Cardiovascular & 1.22 & 1.15 & 1.29 \\
\hline Respiratory & 0.44 & 0.42 & 0.47 \\
\hline Renal & 1.08 & 0.84 & 1.39 \\
\hline Gastrointestinal & 0.85 & 0.79 & 0.91 \\
\hline $\begin{array}{l}\text { Hematologic/ } \\
\text { immunodeficiency }\end{array}$ & 0.53 & 0.43 & 0.65 \\
\hline Metabolic & 0.65 & 0.60 & 0.71 \\
\hline Malignancy & 0.17 & 0.08 & 0.36 \\
\hline $\begin{array}{l}\text { Other congenital or } \\
\text { genetic disorder }\end{array}$ & 1.92 & 1.80 & 2.04 \\
\hline
\end{tabular}

OR, Odds ratio; $\mathrm{LCl}$, lower confidence interval; $\mathrm{UCl}$, upper confidence interval.

patients with cachexia and debility was $\$ 6.55$ million and \$2.06 million, respectively.

Cachexia significantly increased the risk of inpatient death (Table 3). The odds of death increased $60 \%$ when cachexia was present (controlling for characteristics of patients and hospitalizations). However, in patients with debility, the risk of inpatient death was decreased by $40 \%$ but this decrease was not significant. Compared with patients between ages 17 years and 20 years, children aged $\leq 4$ years had a $10 \%$ greater risk of death. For all conditions, self-paying patients had a significantly increased risk of death compared with those paying private insurance. Self-pay status more than doubled the risk of inpatient death for all hospitalized children and adolescents with CCCs. The highest increase in risk of inpatient death was seen with major and extreme losses of function, regardless of the diagnosis.

Cachexia and debility significantly increased the duration of stay (Table 4). Cachexia was associated with a $17 \%$ increase in duration of stay compared with patients without cachexia (controlling for characteristics of patients and hospitalizations). Debility was associated with a $39 \%$ increase in duration of stay compared with patients without debility. Children aged $\leq 4$ years stayed $82 \%$ longer in hospital than patients aged between 17 years and 20 years. The risk of death was increased in self-paying patients, but the duration of stay was lower in these patients (19\% decrease) compared with those paying private insurance.

Debility significantly increased the cost of hospitalization (Table 5). Debility was associated with a $50 \%$ increase in 
Table 4. Predictors of hospitalization stay for children and adolescents with complex chronic conditions (negative binomial regression model).

\begin{tabular}{|c|c|c|c|}
\hline & IRR & LCI & UCI \\
\hline \multicolumn{4}{|l|}{ Cachexia } \\
\hline Not diagnosed & \multicolumn{3}{|c|}{ Reference } \\
\hline Diagnosed & 1.17 & 1.10 & 1.26 \\
\hline \multicolumn{4}{|l|}{ Debility } \\
\hline Not diagnosed & \multicolumn{3}{|c|}{ Reference } \\
\hline Diagnosed & 1.39 & 1.24 & 1.56 \\
\hline \multicolumn{4}{|l|}{ Age (years) } \\
\hline$\leq 4$ & 1.82 & 1.80 & 1.84 \\
\hline $5-8$ & 0.98 & 0.97 & 1.00 \\
\hline $9-12$ & 1.03 & 1.02 & 1.05 \\
\hline $12-16$ & 1.05 & 1.05 & 1.07 \\
\hline $17-20$ years & \multicolumn{3}{|c|}{ Reference } \\
\hline \multicolumn{4}{|l|}{ Ethnicity } \\
\hline Caucasian & \multicolumn{3}{|c|}{ Reference } \\
\hline African-American & 1.08 & 1.07 & 1.09 \\
\hline Hispanic & 0.99 & 0.98 & 1.00 \\
\hline Other & 1.03 & 1.02 & 1.04 \\
\hline \multicolumn{4}{|l|}{ Sex } \\
\hline Female & \multicolumn{3}{|c|}{ Reference } \\
\hline Male & 0.98 & 0.98 & 0.99 \\
\hline \multicolumn{4}{|l|}{ Region } \\
\hline North East & \multicolumn{3}{|c|}{ Reference } \\
\hline Midwest & 0.93 & 0.92 & 0.94 \\
\hline South & 0.95 & 0.94 & 0.96 \\
\hline West & 0.95 & 0.94 & 0.95 \\
\hline \multicolumn{4}{|l|}{ Hospital location } \\
\hline Rural & \multicolumn{3}{|c|}{ Reference } \\
\hline Urban (non-teaching) & 1.49 & 1.47 & 1.52 \\
\hline Urban (teaching) & 1.58 & 1.55 & 1.61 \\
\hline
\end{tabular}

\begin{tabular}{|c|c|c|c|}
\hline \multicolumn{4}{|l|}{ Expected primary payer } \\
\hline Private & \multicolumn{3}{|c|}{ Reference } \\
\hline Medicare & 0.90 & 0.87 & 0.93 \\
\hline Medicaid & 1.03 & 1.02 & 1.04 \\
\hline Self-payer & 0.81 & 0.79 & 0.82 \\
\hline \multicolumn{4}{|l|}{ Loss of function (\%) } \\
\hline Minor & \multicolumn{3}{|c|}{ Reference } \\
\hline Moderate & 1.85 & 1.84 & 1.87 \\
\hline Major & 4.07 & 4.04 & 4.11 \\
\hline Extreme & 8.77 & 8.69 & 8.86 \\
\hline \multicolumn{4}{|l|}{ Median household income } \\
\hline First quartile (Lowest) & 1.03 & 1.02 & 1.04 \\
\hline Second quartile & 1.02 & 1.01 & 1.03 \\
\hline Third quartile & 1.01 & 1.00 & 1.02 \\
\hline Fourth quartile (highest) & \multicolumn{3}{|c|}{ Reference } \\
\hline \multicolumn{4}{|c|}{ Body system affected (reference is not affected) } \\
\hline Neuromuscular & 1.17 & 1.15 & 1.19 \\
\hline Cardiovascular & 1.47 & 1.45 & 1.49 \\
\hline Respiratory & 1.98 & 1.95 & 2.00 \\
\hline Renal & 1.09 & 1.05 & 1.13 \\
\hline Gastrointestinal & 1.19 & 1.17 & 1.20 \\
\hline $\begin{array}{l}\text { Hematologic/ } \\
\text { immunodeficiency }\end{array}$ & 1.07 & 1.05 & 1.09 \\
\hline Metabolic & 1.57 & 1.55 & 1.59 \\
\hline Malignancy & 1.15 & 1.13 & 1.18 \\
\hline $\begin{array}{l}\text { Other congenital or genetic } \\
\text { disorder }\end{array}$ & 0.98 & 0.97 & 0.99 \\
\hline
\end{tabular}

IRR, Incidence rate ratio; $\mathrm{LCl}$, lower confidence interval; $\mathrm{UCl}$, upper confidence interval.

hospitalization costs compared with patients without debility (controlling for characteristics of patients and hospitalizations). Cachexia was associated with an $8 \%$ decrease in hospitalization cost. Compared with patients aged between 17 years and 20 years, care for children aged $\leq 4$ years cost $14 \%$ more.

\section{Discussion}

Our exploratory study found unique differences in children and adolescents with CCCs with comorbid cachexia and debility. Cachexia was more frequently listed on discharge summaries for pediatric CCC hospitalizations than debility. Importantly, cachexia and debility were listed together only rarely as comorbidities. We estimated the incidence of hospitalizations related to cachexia to be $\approx 1,400$

hospitalizations during the sample period. However, the sample included only four years' worth of data. Thus, the incidence of these hospitalizations was likely to be $>3,100$ discharges across 2003-2012. Similarly, our estimate of the incidence of debility-related hospitalizations was lower than the actual value. It is likely that the actual incidence of debility-related hospitalizations was closer to 950 discharges across 2003-2012.

For both conditions, there was a notable increase in the incidence of hospitalization, increasing twofold for cachexia and a remarkable six-fold for debility from 2003 to 2012. This phenomenon may be an effect of the increase in scientific and clinical awareness of cachexia in recent years (which has led to better understanding of its pathophysiology) along with 
Table 5. Predictors of hospitalization cost in children and adolescents with complex chronic conditions (negative binomial model).

\begin{tabular}{|c|c|c|c|}
\hline & IRR & LCI & UCI \\
\hline \multicolumn{4}{|l|}{ Cachexia } \\
\hline Not diagnosed & \multicolumn{3}{|c|}{ Reference } \\
\hline Diagnosed & 0.92 & 0.83 & 1.01 \\
\hline \multicolumn{4}{|l|}{ Debility } \\
\hline Not Diagnosed & \multicolumn{3}{|c|}{ Reference } \\
\hline Diagnosed & 1.50 & 1.24 & 1.80 \\
\hline \multicolumn{4}{|l|}{ Age (years) } \\
\hline$\leq 4$ & 1.14 & 1.13 & 1.16 \\
\hline $5-8$ & 1.02 & 1.00 & 1.04 \\
\hline $9-12$ & 1.06 & 1.04 & 1.08 \\
\hline $13-16$ & 1.07 & 1.06 & 1.09 \\
\hline $17-20$ & \multicolumn{3}{|c|}{ Reference } \\
\hline \multicolumn{4}{|l|}{ Ethnicity } \\
\hline Caucasian & \multicolumn{3}{|c|}{ Reference } \\
\hline African-American & 0.99 & 0.98 & 1.00 \\
\hline Hispanic & 1.03 & 1.02 & 1.04 \\
\hline Other & 0.98 & 0.97 & 0.99 \\
\hline \multicolumn{4}{|l|}{ Sex } \\
\hline Female & \multicolumn{3}{|c|}{ Reference } \\
\hline Male & 1.02 & 1.01 & 1.02 \\
\hline \multicolumn{4}{|l|}{ Region } \\
\hline North East & \multicolumn{3}{|c|}{ Reference } \\
\hline Midwest & 0.82 & 0.81 & 0.83 \\
\hline South & 0.73 & 0.72 & 0.74 \\
\hline West & 1.10 & 1.09 & 1.11 \\
\hline \multicolumn{4}{|l|}{ Hospital location } \\
\hline Rural & \multicolumn{3}{|c|}{ Reference } \\
\hline Urban (non-teaching) & 1.44 & 1.41 & 1.47 \\
\hline Urban (teaching) & 2.06 & 2.02 & 2.10 \\
\hline
\end{tabular}

\begin{tabular}{|c|c|c|c|}
\hline \multicolumn{4}{|l|}{ Expected primary payer } \\
\hline Private & \multicolumn{3}{|c|}{ Reference } \\
\hline Medicare & 0.93 & 0.89 & 0.97 \\
\hline Medicaid & 0.96 & 0.95 & 0.97 \\
\hline Self-payer & 0.72 & 0.71 & 0.74 \\
\hline Loss of function (\%) & 1.07 & 1.05 & 1.09 \\
\hline Minor & \multicolumn{3}{|c|}{ Reference } \\
\hline Moderate & 1.79 & 1.77 & 1.81 \\
\hline Major & 4.56 & 4.51 & 4.61 \\
\hline Extreme & 12.06 & 11.90 & 12.21 \\
\hline \multicolumn{4}{|l|}{ Median household income } \\
\hline First quartile (lowest) & 0.93 & 0.92 & 0.94 \\
\hline Second quartile & 0.94 & 0.93 & 0.95 \\
\hline Third quartile & 0.95 & 0.94 & 0.96 \\
\hline Fourth quartile (Highest) & \multicolumn{3}{|c|}{ Reference } \\
\hline \multicolumn{4}{|c|}{ Body system affected (reference is not affected) } \\
\hline Neuromuscular & 0.86 & 0.85 & 0.88 \\
\hline Cardiovascular & 1.43 & 1.41 & 1.45 \\
\hline Respiratory & 1.66 & 1.64 & 1.69 \\
\hline Renal & 1.01 & 0.96 & 1.05 \\
\hline Gastrointestinal & 1.19 & 1.17 & 1.21 \\
\hline Hematologic & 1.11 & 1.08 & 1.14 \\
\hline Metabolic & 1.42 & 1.39 & 1.44 \\
\hline Malignancy & 1.36 & 1.32 & 1.40 \\
\hline Other & 1.20 & 1.18 & 1.22 \\
\hline
\end{tabular}

IRR, Incidence rate ratio; LCl: lower confidence interval; $\mathrm{UCl}$, upper confidence interval.

advancements in clinical interventions to arrest its progress [2]. No such advances have been made in understanding and addressing debility. Consistent with previous studies, we found that among all patient groups, inpatient death was reported more often in patients with cachexia than in those with debility. In our regression model, cachexia was a more robust predictor of inpatient death compared with debility.

Our previous study on cachexia with hospitalized adults in the USA established an increased medical burden of loss of function in patients with cachexia [24]. In the present study, we found a similar correlation between cachexia and loss of function, as well as debility. This finding regarding loss of function in patients with debility might be intuitive. Importantly, patients with debility experienced more extreme loss of function when compared to those with cachexia. This finding may be explained by the similarity in the ontologies of debility and loss of function. Interestingly, cachexia and debility were associated with similar CCCs, including metabolic and neuromuscular diseases.

The relationship between cachexia, debility, and metabolic diseases is plausible because skeletal muscle contains tissue with the highest metabolic demands in the body. In addition, with degeneration of motor units, muscle wasting and loss of strength is inevitable. Therefore, cachexia and debility are expected in neuromuscular diseases [25]. However, cachexia was highly associated with hematologic disorders, but debility was not. Anemia is a characteristic of cachexia and cachexia is associated with infection by HIV, so it is pertinent that our findings demonstrate a prevalence of cachexia in children diagnosed with hematologic disorders. In addition, levels of 
tumor necrosis factor-alpha (TNF-a) are elevated in children with anemia, including sickle-cell anemia; TNF- $a$ is known to exacerbate cachexia $[26,27]$.

Debility was highly associated with cardiovascular disorders and cachexia was not. Cachexia and muscle wasting may not be prevalent with pediatric cardiovascular disease. Weakness, which is a characteristic of debility, is also a hallmark of cardiac dysfunction. CCCs in children are usually from birth or in the early stages of development of children. Pediatric quality of life is significantly affected by cardiovascular disease [28]. This effect may be manifested as debility in children with cardiovascular disease.

HIV infections were the most common primary diagnosis for children with cachexia. This observation is translated from observations in studies with adult patients in whom cachexiabased neuropathy was found to be a primary neuropathy in HIV [29]. Consistent with earlier findings, the predominant procedural intervention in patients with debility was related to the heart and in patients with cachexia (they were related to infusion-based treatments usually associated with hematologic disorders and malnutrition).

A remarkable observation in exploring payer status between patients with cachexia and patients with debility was seen in the distribution of Medicaid as the primary payer between the two groups. More hospitalizations with cachexia had Medicaid as the primary payer than that for hospitalizations with debility. This phenomenon may be seen as an approximation of the relative difference in the moribund nature of cachexia and debility. Cachexia is usually associated with terminal conditions, which carry a tremendous financial burden. Such cases are primarily given Medicaid enrollment, especially for endof-life care. Debility resulted in a significantly longer duration of stay and higher cost during hospitalizations compared with cachexia. This difference may be attributed to a predominance of surgical procedures associated with hospitalizations with debility when compared with those for cachexia.

This study had several limitations. An important limitation of the KID is that new release of data is available only every third year. The KID was selected because it includes an $80 \%$ sample of pediatric hospitalizations, thereby allowing for the study of rare diseases. However, we were unable to speculate about hospitalizations that occur during the years in which there is not a KID data release. An alternative database that could be accessed readily is the Nationwide Inpatient Sample (NIS; recently renamed as the "National Inpatient Sample"). The NIS includes a $20 \%$ sample of hospitalizations occurring at nonfederal community hospitals each year. The NIS would allow us to examine the frequency and characteristics of cachexia- and debility-related hospitalizations in a more continuous fashion across years. However, the NIS is not age-specific and has a smaller sampling frame, so we may not be able to capture these rare conditions with as much precision. In a future contribution, we plan to validate the present study in the NIS to see if the observed trends hold true for the years in which we were unable to examine data using the KID.

Based on the data elements included in the KID, we relied on ICD-9-CM diagnoses of cachexia and debility (binary measures) rather than symptomology, scales, and clinical data. An important limitation of the KID is the potential for miscoding, which we could not reconcile with clinical data. The data in the KID are de-identified, so it is not possible to verify a discharge record with clinical data for individual patients. Diagnoses of cachexia and debility may be encoded in a patient's discharge record when the condition is most pronounced in its manifestations. This strategy is supported by the fact that the vast majority of discharges with cachexia and debility were accompanied by major or extreme losses of function. By relying on diagnoses rather than symptoms, we may have understated the disease burden of these two conditions in children and adolescents with CCCs. Further clinical study is needed to confirm the burden of cachexia and debility in children and adolescents with CCCs.

\section{Conclusion}

This study is the first to describe the impact of cachexia and debility on children and adolescents with CCCs. Both conditions are prevalent in children with metabolic and neuromuscular diseases. With increases in diagnoses of cachexia and debility, as well as an increased incidence of hospitalization, cachexia and debility contribute to a significant medical burden to children and adolescents with CCCs. We believe that our findings may be useful in the refinement of definitions of cachexia and debility, and perhaps development of treatments for these conditions that would assist in combatting metabolic, hematological, cardiovascular, and neuromuscular diseases in children. By helping to clarify these conditions, our study may assist in identification of cachexia and debility at earlier stages of CCCs, which will be useful in delaying precipitous decline in quality of life.

\section{Contributions}

- Concept and design; acquisition, analysis and interpretation of data; manuscript preparation; revision for important intellectual content: Bryce A. Van Doren

- Concept and design: Susan T. Arthur

- Interpretation, manuscript preparation, and revision for important intellectual content: Debosree Roy, Joshua M. Noone, Christopher M. Blanchette, and Susan T. Arthur

\section{Potential conflicts of interest}

The International Committee of Medical Journal Editors' (ICMJE) Potential Conflicts of Interests forms for the authors are available for download at: http://www.drugsincontext.com/ wp-content/uploads/2015/02/dic.212277-COI.pdf 


\section{Funding declaration}

None to declare.

\section{Acknowledgement}

We acknowledge that the data used for this project, the Kids' Inpatient Sample, were acquired from the Healthcare Cost and Utilization Project, Agency for Healthcare Research and Quality.

\section{References}

1. lezzoni LI. Using administrative diagnostic data to assess the quality of hospital care: Pitfalls and potential of ICD9-CM. Int J Technol Assess Health Care. 1990;6(2):272-81. PubMed PMID: 2203703. http://dx.doi.org/10.1017/S0266462300000799

2. Muscaritoli M, Anker SD, Argiles J, Aversa Z, Bauer JM, Biolo G, Boirie Y, Bosaeus I, Cederholm T, Costelli P, Fearon KC, Laviano A, Maggio M, Rossi-Fanelli F, Schneider SM, Schols A, Sieber CC. Consensus definition of sarcopenia, cachexia and pre-cachexia: joint document elaborated by Special Interest Groups (SIG) "CachexiaAnorexia in Chronic Wasting Diseases" and "Nutrition in Geriatrics". Clin Nutr. 2010;29(2):154-9. PubMed PMID: 20060626.

http://dx.doi.org/10.1016/j.clnu.2009.12.004

3. Dewys WD, Begg C, Lavin PT, Band PR, Bennett JM, Bertino JR, Cohen MH, Douglass HO Jr, Engstrom PF, Ezdinli EZ, Horton J, Johnson GJ, Moertel CG, Oken MM, Perlia C, Rosenbaum C, Silverstein MN, Skeel RT, Sponzo RW, Tormey DC. Prognostic effect of weight loss prior to chemotherapy in cancer patients. Amer J Med. 1980;69(4):491-7. PubMed PMID: 7424938.

4. Kinzbrunner BM, Weinreb NJ, Merriman MP. Debility, unspecified: A terminal diagnosis. Am J Hosp Palliat Care. 1996;13(6):38-44. PubMed PMID: 8945102. http://dx.doi.org/10.1177/ 104990919601300614

5. Bauer J, Jürgens H, Frühwald MC. Important aspects of nutrition in children with cancer. Adv Nutr. 2011;2(2):67-77. PubMed PMID: 22332035.

http://dx.doi.org/10.3945/an.110.000141

6. Brinksma A, Huizinga G, Sulkers E, Kamps W, Roodbol P, Tissing W. Malnutrition in childhood cancer patients: a review on its prevalence and possible causes. Crit Rev Oncol Hematol. 2012;3(2):249-75. PubMed PMID: 22264939.

http://dx.doi.org/10.1016/j.critrevonc.2011.12.003

7. Burnham JM, Shults J, Semeao E, Foster BJ, Zemel BS, Stallings VA, Leonard MB. Body-composition alterations consistent with cachexia in children and young adults with Crohn disease. Am J Clin Nutr. 2005;82(2):413-20. PubMed PMID: 16087987.
8. Cheung WW, Paik KH, Mak RH. Inflammation and cachexia in chronic kidney disease. Pediatr Nephrol. 2010;25(4):

711-24. PubMed PMID: 20111974.

http://dx.doi.org/10.1007/s00467-009-1427-z

9. Mak RH, Cheung WW, Zhan JY, Shen Q, Foster BJ. Cachexia and protein-energy wasting in children with chronic kidney disease. Pediatr Nephrol. 2012;27(2):173-81. PubMed PMID: 21298504.

http://dx.doi.org/10.1007/s00467-011-1765-5

10. Tsoli M, Robertson G. Cancer cachexia: malignant inflammation, tumorkines, and metabolic mayhem. Trends in Endocrinol Metab. 2013;24(4):174-83. PubMed PMID: 23201432. http://dx.doi.org/10.1016/j.tem.2012.10.006

11. Feudtner C, Christakis DA, Connell FA. Pediatric deaths attributable to complex chronic conditions: a populationbased study of Washington State, 1980-1997. Pediatrics. 2000;106(1 Pt 2):205-9. PubMed PMID: 10888693.

12. Himelstein BP. Palliative care for infants, children, adolescents, and their families. J Palliat Med. 2006; 9(1):163-81. PubMed PMID: 16430356. http://dx.doi.org/10.1089/jpm.2006.9.163

13. Evans WJ, Morley JE, Argilés J, Bales C, Baracos V, Guttridge D, Jatoi A, Kalantar-Zadeh K, Lochs H, Mantovani G, Marks D, Mitch WE, Muscaritoli M, Najand A, Ponikowski P, Rossi Fanelli F, Schambelan M, Schols A, Schuster M, Thomas D, Wolfe R, Anker SD. Cachexia: a new definition. Clin Nutr. 2008;27(6):793-9. PubMed PMID: 18718696. http://dx.doi.org/10.1016/j.clnu.2008.06.013

14. Fearon K, Strasser F, Anker SD, Bosaeus I, Bruera E, Fainsinger RL, Jatoi A, Loprinzi C, MacDonald N, Mantovani G, Davis M, Muscaritoli M, Ottery F, Radbruch L, Ravasco P, Walsh D, Wilcock A, Kaasa S, Baracos VE. Definition and classification of cancer cachexia: an international consensus. Lancet Oncol. 2011;12(5):489-95. PubMed PMID: 21296615. http://dx.doi.org/ 10.1016/s1470-2045(10)70218-7

15. Blum D, Stene GB, Solheim TS, Fayers P, Hjermstad MJ, Baracos VE, Fearon K, Strasser F, Kaasa S, Euro-Impact. Validation of the Consensus-Definition for Cancer Cachexia and evaluation of a classification model-a study based on data from an international multicentre project (EPCRC-CSA). Ann Oncol. 2014;25(8):1635-42. PubMed PMID: 24562443.

http://dx.doi.org/10.1093/annonc/mdu086

16. National Hospice and Palliative Care Organization. NHPCO's Facts and Figures: Hospice Care in America. Available at: http://www.nhpco.org/sites/default/files/public/Statistics_ Research/2014_Facts_Figures.pdf. [Last accessed: January 15, 2015].

17. Mak RH, Cheung W. Energy homeostasis and cachexia in chronic kidney disease. Pediatr Nephrol. 2006;21(12): 1807-14. PubMed PMID: 16897005. http://dx.doi.org/10.1007/s00467-006-0194-3 
18. Fischbach M, Dheu C, Seuge L, Orfanos N. Hemodialysis and nutritional status in children: malnutrition and cachexia. J Ren Nutr. 2009;19(1):91-4. PubMed PMID: 19121780. http://dx.doi.org/10.1053/j.jrn.2008.10.008

19. Rothenberg LR, Doberman D, Simon LE, Gryczynski J, Cordts G. Patients surviving six months in hospice care: who are they? J Palliat Med. 2014;7(8):899-905. PubMed PMID: 24933676.

http://dx.doi.org/10.1089/jpm.2013.0512

20. Aktas A, Rybicki LA, Walsh D. The impact of symptom clusters on survival in patients with advanced cancer. Poster presented at 2010 ASCO Annual Meeting; 2010 June 4-8; Chicago, Illinois. Reprinted in J Clin Oncol. 2010;28(15):9145.

21. Warmenhoven F, van Weel C, Vissers K, Prins J. Screening instruments for depression in advanced cancer patients: what do we actually measure? Pain Pract. 2013;3(6):467-75. PubMed PMID: 23157987. http://dx.doi.org/10.1111/papr.12012

22. Inui A. Cancer anorexia-cachexia syndrome: current issues in research and management. CA Cancer J Clin. 2002;52(2):72-91. PubMed PMID: 11929007. http://dx.doi.org/10.3322/canjclin.52.2.72

23. Simon TD, Berry J, Feudtner C, Stone BL, Sheng X, Bratton $\mathrm{SL}$, Dean JM, Srivastava R. Children with complex chronic conditions in inpatient hospital settings in the United States. Pediatrics. 2010;126(4):647-55. PubMed PMID: 20855394. http://dx.doi.org/10.1542/peds.2009-3266
24. Arthur ST, Noone JM, Van Doren BA, Roy D, Blanchette CM. One-year prevalence, comorbidities and cost of cachexiarelated inpatient admissions in the USA. Drugs Context. 2014;3:212265. PubMed PMID: 25126097. http://dx.doi.org/10.7573/dic.212265

25. Sakuma K, Yamaguchi A. Sarcopenia and cachexia: the adaptations of negative regulators of skeletal muscle mass. J Cachexia Sarcopenia Muscle. 2012;3(2):77-94. PubMed PMID: 22476916. http://dx.doi.org/10.1007/s13539-011-0052-4

26. Kuvibidila S, Gardner R, Ode D, Yu L, Lane G, Warrier RP. Tumor necrosis factor alpha in children with sickle cell disease in stable condition. J Natl Med Assoc. 1997;89(9): 609-15. PubMed PMID: 9302858.

27. Kuvibidila S, Yu L, Gardner R, Velez M, Ode D, Warrier RP. Association between increased levels of TNF-alpha, decreased levels of prealbumin and retinol-binding protein, and disease outcome. J Natl Med Assoc. 2000;92(10):485-91. PubMed PMID: 11105729.

28. Uzark K, Jones K, Slusher J, Limbers CA, Burwinkle TM, Varni JW. Quality of life in children with heart disease as perceived by children and parents. Pediatrics. 2008;121(5): e1060-7. PubMed PMID: 18450848. http://dx.doi.org/10.1542/peds.2006-3778

29. Verma A. Epidemiology and clinical features of HIV-1 associated neuropathies. J Peripher Nerv Syst. 2001; 6(1):8-13. PubMed PMID: 11293807. http://dx.doi.org/10.1046/j.1529-8027.2001.006001008.x 
Appendix 1. International Classification of Disease, $9^{\text {th }}$ Revision (ICD-9) codes for complex chronic conditions, cachexia, and debility.

\begin{tabular}{|c|c|}
\hline Body system & ICD-9-CM code \\
\hline \multicolumn{2}{|l|}{ Neuromuscular } \\
\hline $\begin{array}{l}\text { Brain and spinal cord } \\
\text { malformations }\end{array}$ & $740.0-742.9$ \\
\hline Mental retardation & $318.0-319.0$ \\
\hline CNS degeneration and disease & 330.0-337.9 \\
\hline Infantile cerebral palsy & $343.0-343.9$ \\
\hline Epilepsy & $345.0-345.9$ \\
\hline Muscular dystrophies & $359.0-359.3$ \\
\hline \multicolumn{2}{|l|}{ Cardiovascular } \\
\hline $\begin{array}{l}\text { Heart and great vessel } \\
\text { malformations }\end{array}$ & $745.0-747.49$ \\
\hline Cardiomyopathies & $425.0-425.4,429.1$ \\
\hline $\begin{array}{l}\text { Conduction disorders and } \\
\text { dysrhythmias }\end{array}$ & $\begin{array}{l}426.0-427.4 \\
427.6-427.9\end{array}$ \\
\hline \multicolumn{2}{|l|}{ Respiratory } \\
\hline Respiratory malformations & 748.0-748.9 \\
\hline Chronic respiratory disease & 770.7 \\
\hline Cystic fibrosis & \\
\hline \multicolumn{2}{|l|}{ Renal } \\
\hline Congenital anomalies & 753.0-753.9 \\
\hline Chronic renal failure & 585 \\
\hline \multicolumn{2}{|l|}{ Gastrointestinal } \\
\hline Congenital anomalies & $\begin{array}{l}\text { 750.3, 751.1-751.3, } \\
751.6-751.9\end{array}$ \\
\hline Chronic liver disease and cirrhosis & $571.4-571.9$ \\
\hline Inflammatory bowel disease & 550.556 .9 \\
\hline
\end{tabular}

\begin{tabular}{|c|c|}
\hline Body system & ICD-9-CM code \\
\hline \multicolumn{2}{|l|}{$\begin{array}{l}\text { Hematology and } \\
\text { immunodeficiency }\end{array}$} \\
\hline Sickle-cell disease & $282.5-282.6$ \\
\hline Hereditary anemias & $282.0-282.4$ \\
\hline Hereditary immunodeficiency & $\begin{array}{l}\text { 279.0-279.9, } \\
288.1-288.2,446.1\end{array}$ \\
\hline Human immunodeficiency virus & 42 \\
\hline \multicolumn{2}{|l|}{ Metabolic } \\
\hline Amino acid metabolism & $270.0-270.9$ \\
\hline Carbohydrate metabolism & 271.0-271.9 \\
\hline Lipid metabolism & $272.0-272.9$ \\
\hline Storage disorders & $277.3,277.5$ \\
\hline Other metabolic disorders & $\begin{array}{l}275.0-275.3,277.2, \\
277.4,277.6, \\
277.8-277.9\end{array}$ \\
\hline \multicolumn{2}{|l|}{ Other congenital or genetic defect } \\
\hline Chromosomal anomalies & $758.0-758.9$ \\
\hline Bone and joint anomalies & $\begin{array}{l}259.4,737.3 \\
756.0-756.5\end{array}$ \\
\hline $\begin{array}{l}\text { Diaphragm and abdominal wall } \\
\text { defects }\end{array}$ & $553.3,756.6-756.7$ \\
\hline Other congenital anomalies & 759.7 \\
\hline \multicolumn{2}{|l|}{ Malignancy } \\
\hline Malignancy & $140.0-239.9$ \\
\hline \multicolumn{2}{|l|}{ Cachexia and debility } \\
\hline Cachexia & 799.4 \\
\hline Debility & 799.3 \\
\hline
\end{tabular}

